\title{
Special issue on applications of air quality in science and engineering
}

\author{
Mohamed F. Yassin ${ }^{1}$
}

Published online: 18 December 2021

(c) Islamic Azad University (IAU) 2021

Air quality applications in science and engineering have become an important topic globally, particularly in megacities and urban environments. Rapid city expansion, urbanization, and sustainable development of the urban environment are now facing global challenges. In addition, rapid industrial development coupled with emissions from the transport sector is recognized as the prime source of air pollution. Natural sources, such as sand and dust storms, also add to the air pollution burden. The situation is alarming and gradually becoming more severe, and the severity is expected to increase with population expansion. Either natural or anthropogenic sources may cause air pollution, and the latter is broadly categorized through industrial, commercial, and vehicular activities.

This special issue of the International Journal of Environmental Science and Technology (IJEST) comprises 30 papers selected from the First International Conference on Applications of Air Quality in Science and Engineering (ICAAQSE), held at the Badria Hall, Jumeirah Messilah Beach Hotel \& Spa in Kuwait City, Kuwait, on 10-12 February 2020. The ICAAQSE 2020 conference was an international hub of dissemination of air quality studies, research, and their applications in science and engineering. The conference aimed to bring together leading academic scientists, researchers, and scholars to exchange and share their experiences, practices, and results about all aspects of air quality and its applications in science and engineering. It also provided the premier interdisciplinary forum for scientists, researchers, practitioners, government officials, and educators to present and discuss the most recent innovations, trends, concerns, and practical challenges encountered and the solutions adopted in air quality and its applications in science and engineering. The outcome of such research needs to be contextualized within well-formulated

Mohamed F. Yassin

mohamed_f_yassin@hotmail.com

1 Environment and Life Sciences Research Center (ELSRC), Kuwait Institute for Scientific Research (KISR), PO Box 24885, 13109 Safat, Kuwait communication strategies that help the policymakers and the citizens to understand and appreciate the risks and rewards arising from air quality management.

The ICAAQSE 2020 conference attracted about 400 participants from more than 40 countries. The total submitted papers were 170 covering the problems in the outdoor/ indoor environment of the ICAAQSE 2020 conference. The scientific committee selected only 110 papers that included 96 oral presentations and 14 poster presentations. The participants were from World Health Organization (WHO) and from more than 34 counties, e.g. Kuwait, Jordan, United Arab Emirates, Saudi Arabia, Qatar, Oman, Egypt, Palestine, Iraq, India, Bangladesh, Pakistan, Nepal, Malaysia, Brunei, Nigeria, South Africa, Cyprus, Slovenia, Finland, Belgium, Italy, Turkey, Iran, Japan, UK, USA, and Canada.

Four special lectures were presented in the conference, which are the following:

1) Urban air quality Current Threats and Opportunities, by Professor Roy Harrison, University of Birmingham, United Kingdom,

2) Urban Air Pollution and Management, by Professor Heekawn Lee, Incheon National University, Korea,

3) Air quality and climate-resilient cities Air Quality and Climate-Resilient Cities: A Modeling Approach, by Professor Ana Isabel Miranda, Universidade de Aveiro, Portugal,

4) Air quality and health in kuwait Lessons and Future Direction, by Professor Petros Koutrakis, Harvard T.H. Chan School of Public Health, USA.

\section{The ICAAQSE 2020 recommendations}

- Recognizing the importance of regional research studies on air quality and its impact on human health to improve the living environment of our citizens;

- Realizing the urgency for regional networking and cooperation in scientific research in the area of air quality and its regional impact on social and economic development; 
- Appreciating the efforts made by national research institutes and universities in the research studies of air quality, and urging them to increase the publication and studies in this field; and

- Urging the policymakers for more engagement to strategize this issue and minimize the impact of air quality on human health and sustainable development.

In the first international conference on Applications of Air Quality in Science and Engineering ICAAQSE 2020, held for three days at the Kuwait Institute for Scientific Research (KISR), Kuwait, around 400 participants of scientists and experts from 40 countries have made the following recommendations:

1. Acknowledge the effort made by KISR to organize the first International Conference on Applications of Air Quality in Science and Engineering (ICAAQSE).

2. Establish a regional committee to strategize this critical issue for the Arab Region and promote the strategic studies, cooperation, networking, strategic guidance, research studies, and action plans for the benefit of our region.

3. Urge the committee of the ICAAQSE 2020 to strengthen its cooperation with the Aerosol Association for the Middle East and North Africa (AAMENA) to foster collaboration and encourage more participation in the AAMENA membership.

4. Promote regional studies in air quality and its impact on health, particularly the direct impact on morbidity and mortality and cultural heritage.

5. Urge policymakers and scientists to develop a mechanism for coordination among stakeholders to increase cross-fertilization and sharing of relevant information and experiences.

6. Map and identify the key stakeholders, users, and beneficiaries and their roles and activities to maximize the value and reduce redundancy risks.

7. Develop an awareness mechanism among stakeholders, the public, and NGOs about the impact of air quality on human health and on ways to save our life.

8. Ensuring the continuity of this valuable conference to be organized biannually.

9. Encourage more studies on the air quality interdisciplinary thematic areas, including modeling, forecasting, climate changes, and health implications.

10. Urge academia to revise and promote educational programs, curriculum, and training courses for capacity development among human capital in the region.

11. Create a database of the available national air quality data (lengthlperiod, parameters, contact person, etc.) and the possible sharing for evaluation of regional models.

12. Encourage local private sector to engage more and conduct studies in air quality.

As Guest Editor and Associate Editor, I would like to thank all the reviewers, fellow IJEST editors, editorial assistants, and the production team for their hard work and contribution to this special issue. I would also like to thank Prof. Madjid Abbaspour (Editor-in-Chief), Ms. Samareh Mirkia (Managing Editor), and Ms. Maryam Shabani (Editor) for their coordination in publishing this special issue in IJEST. 